\title{
A Numerical Study for Predicting Steam Ejector Performance at Different Pressure Ratios
}

\author{
M. S. Farag*
}

\begin{abstract}
This paper presents a numerical study for predicting the steam ejector performance for different pressure ratios. The considered steam ejector operates at small pressure ratios of back to motive pressures. Both the suction and motive fluids are regarded to be dry steam. Due to low pressure created by the motive steam nozzle flow, entrainment of steam to be mixed with motive steam where both resume flowing toward the ejector exit. Mass ratio of suction to motive flows is an important element to describe the ejector performance.The present study aims to optimize the steam ejector efficiency that runs at different pressure ratio for each suction pressure. The variation of the mass ratio and ejector efficiency with the ejector back pressure at different values of the suction pressure and constant motive pressure, also a variation of the mass ratio and ejector efficiency with the ejector back pressure at different values of the motive pressure and constant suction pressure are investigated. The numerical results are validated with the available experiments from the literature. The results show that the mass ratio is almost constant at low values of back pressure, depending on the suction and back pressures, then the mass ratio decreases sharply with increasing the back pressure. The suction pressure has the positive consequence on the mass ratio. Moreover, the results show that the ejector efficiency increases with increasing the back pressure to gain its upper limit value, subsequently that the efficiency decreases with raising the back pressure. Also, raising the suction pressure will cause an improvement in the ejector efficiency. The value of back pressure at which the maximum efficiency is achieved and its value increases with magnifying the suction pressure.
\end{abstract}

Keywords: Desalination System, Steam Ejector, Mass Ratio, Ejector Efficiency, CFD

\section{Introduction}

The ejector can be utilized for different purposes because of its simple construction and easy operation. High pressure driving fluid in the ejector is known as motive fluid. The driving motive fluid flows through a motive nozzle to suck the suction fluid. The two fluids are mixed in the mixing duct and then the mixture flows through the diffuser where the pressure recovery occurs. Ideally, there is an exchange of momentum at this point producing uniformly mixed stream flow travelling at an intermediate velocity between the motive and suction velocities. A tail diffuser is installed to reduce the resulting velocity gradually and convert the exit kinetic energy from the mixing chamber to a pressure with a little loss as possible.

For many years, the computational fluid dynamics (CFD) technique has proved to be an efficient tool for flow field analysis and ejector performance predictions. A number of CFD investigations have been carried out to study the effect of ejector geometry on its performance, e.g. nozzle exit position (NXP), the area ratio of nozzle throat to constant area section, and the length of constant area section before and after the throat [1-8]. Yang et al [9] presented numerical investigation on the mixing process in a steam ejector with different

Faculty of Engineering, Menoufia University, Egypt; $\underline{m \_s \_f a r a g @ s h-e n g . m e n o f i a . e d u . e g ~}$ 
nozzle structures at the same conditions. They found that the ejector performance and mixing characteristics are significantly altered by ejector. Sriveerakul et al $[4,10]$ presented a CFD for predicting the steam ejector for refrigeration applications. They discussed the effect of operational and geometric parameters of the steam ejector performance and they found that ejector performance is significantly affected by these parameters. Also, both the ejector operating conditions, and ejector geometries were found to affect its performance. So, justification of the ejector geometry is likely needed for unusual applications $[11,12]$.

The ultimate objective of the present work is testing the steam ejector performance working at low pressure ratios. The main parameters of the steam ejector are the suction to motive mass ratio and its efficiency. This preliminary work can declare the possibility for utilizing the steam ejector with MED/MFD systems. Also, it will may provide desalinated water at lower pressure and temperature instead of superheating the steam.

\section{Mathematical Model}

This section includes the main equations which describe the flow behavior through the ejector. In the present study the theoretical model is formulated based on some assumptions such as: single phase (superheated steam) flow, two-dimensional and compressible flow. We consider a horizontal ejector and the flow is statistically steady and axisymmetric. The water vapor is an ideal gas and its thermodynamic properties vary with temperature. Also, the water vapor flow as a single phase with no condensation.

The conservation of mass or continuity equation can be written $[13,14]$

$$
\frac{\partial}{\partial x}(\rho u)+\frac{\partial}{\partial r}(\rho v)+\frac{\rho v}{r}=0
$$

The equations for momentum conservation are

$$
\begin{aligned}
\frac{\partial}{\partial \mathrm{x}}(\rho \mathrm{uu})+\frac{1}{\mathrm{r}} & \frac{\partial}{\partial \mathrm{r}}(\mathrm{r} \rho \mathrm{uv}) \\
& =-\frac{\partial \mathrm{p}}{\partial \mathrm{x}}+\frac{\partial}{\partial \mathrm{x}}\left[\mu_{\mathrm{eff}}\left(2 \frac{\partial \mathrm{u}}{\partial \mathrm{x}}-\frac{2}{3}(\nabla \cdot \overrightarrow{\mathrm{u}})\right)\right]+\frac{1}{\mathrm{r}} \frac{\partial}{\partial \mathrm{r}}\left[\mathrm{r} \mu_{\mathrm{eff}}\left(\frac{\partial \mathrm{u}}{\partial \mathrm{r}}+\frac{\partial \mathrm{v}}{\partial \mathrm{x}}\right)\right]+\rho \mathrm{g} \\
& +\mathrm{S}_{\mathrm{U}}
\end{aligned}
$$

$$
\begin{gathered}
\frac{\partial}{\partial \mathrm{x}}(\text { puv })+\frac{1}{\mathrm{r}} \frac{\partial}{\partial \mathrm{r}}(\mathrm{r} \rho \mathrm{vv})=-\frac{\partial \mathrm{p}}{\partial \mathrm{r}}+\frac{\partial}{\partial \mathrm{x}}\left[\mu_{\mathrm{eff}}\left(\frac{\partial \mathrm{u}}{\partial \mathrm{r}}+\frac{\partial \mathrm{v}}{\partial \mathrm{x}}\right)\right]+\frac{1}{\mathrm{r}} \frac{\partial}{\partial \mathrm{r}}\left[\mathrm{r} \mu_{\mathrm{eff}}\left(2 \frac{\partial \mathrm{v}}{\partial \mathrm{r}}-\frac{2}{3}(\nabla \cdot \overrightarrow{\mathrm{u}})\right)\right] \\
-2 \mu_{\mathrm{eff}} \frac{\mathrm{v}}{\mathrm{r}^{2}}+\frac{2}{3} \frac{\mu_{\mathrm{eff}}}{\mathrm{r}}(\nabla \cdot \overrightarrow{\mathrm{u}}) \\
+\mathrm{S}_{\mathrm{V}}
\end{gathered}
$$

Here $S_{U}$ and $S_{V}$ are the source terms for momentum in $\mathrm{x}$ and $\mathrm{r}$ directions, respectively, and $\nabla \cdot \overrightarrow{\mathrm{u}}=\frac{\partial \mathrm{u}}{\partial \mathrm{x}}+\frac{\partial \mathrm{v}}{\partial \mathrm{r}}+\frac{\mathrm{v}}{\mathrm{r}}$

The conservation of energy in statistically steady cylindrical coordinate systems are defined as. 
$\frac{\partial}{\partial \mathrm{x}}(\mathrm{u}(\rho E+p))+\frac{1}{\mathrm{r}} \frac{\partial}{\partial \mathrm{r}}(\operatorname{rv}(\rho E+p))=\frac{\partial}{\partial \mathrm{x}}\left[\lambda_{\text {eff }} \frac{\partial \mathrm{T}}{\partial \mathrm{x}}-\sum h_{i} J_{i x}+\left(\overline{\bar{\tau}}_{e f f} \cdot \vec{V}\right)_{x}\right]+$

$\frac{1}{r}\left[r \lambda_{\mathrm{eff}} \frac{\partial \mathrm{T}}{\partial \mathrm{r}}-\sum h_{i} J_{i r}+\left(\overline{\bar{\tau}}_{e f f} \cdot \vec{V}\right)_{r}\right]+\mathrm{S}_{\mathrm{h}}$

where $\overline{\bar{\tau}}_{\text {eff }}$ is the turbulent shear stress tensor, $\vec{V}$ is the velocityvector and $S_{h}$ is the energy source term.

In the above equation, $E=h-\frac{p}{\rho}+\frac{\left(u^{2}+v^{2}\right)}{2}$

whereh is the sensible enthalpy and for compressible flows it is defined as $h=\sum_{i} Y_{i} h_{i}$ and $\mathrm{h}_{\mathrm{i}}=\int_{\mathrm{T}_{\text {ref }}}^{\mathrm{T}} \mathrm{C}_{\mathrm{pi}} \mathrm{dT}$ where $\mathrm{T}_{\text {ref }}$ is the reference temperature and equal to $298.15 \mathrm{~K}$.

the steam ejector efficiency can be given by $[15,16]$.

$\eta_{\text {ejector }}=M R * \frac{\left(h_{b}-h_{s}\right)}{\left(h_{m}-h_{b}\right)}$

where, $h_{b}, h_{s}$, and $h_{m}$ are the enthalpies for the back, suction and motive steam respectively.MR is the mass ratio of suction to motive mass flow rates.

\section{Turbulence Modelling}

The realizable $\mathrm{k}-\varepsilon$ model $[13,14,17]$ was used to model turbulence in the present simulation. Moreover, it is found the this model provides a superior performance of the flows involving rotation, boundary layer under strong adverse pressure gradient and separation that is likely found in steam ejector $[10,13,14]$. The realizable $\mathrm{k}-\varepsilon$ model differs from the standard $\mathrm{k}-\varepsilon$ model in two important parameters. The realizable $\mathrm{k}-\varepsilon$ contains a new formulation for the turbulent viscosity. Moreover, the realizable $\mathrm{k}-\varepsilon$ derived a new transport equation for the dissipation rate, $\varepsilon . \varepsilon$ has been derived from an exact equation for the transport of the meansquare vorticity fluctuation.

The governing equations for the turbulentkinetic energy and the dissipation rate are

$\frac{\partial}{\partial \mathrm{x}}(\rho \mathrm{uk})+\frac{1}{\mathrm{r}} \frac{\partial}{\partial \mathrm{r}}(\mathrm{r} \rho \mathrm{k})=\frac{\partial}{\partial \mathrm{x}}\left[\left(\mu+\frac{\mu_{t}}{\sigma_{k}}\right) \frac{\partial \mathrm{k}}{\partial \mathrm{x}}\right]+\frac{1}{r} \frac{\partial}{\partial \mathrm{r}}\left[r\left(\mu+\frac{\mu_{t}}{\sigma_{k}}\right) \frac{\partial \mathrm{k}}{\partial \mathrm{r}}\right]+G_{k}+G_{b}-\rho \varepsilon+S_{k}$

$\frac{\partial}{\partial \mathrm{x}}(\rho \mathrm{u} \varepsilon)+\frac{1}{\mathrm{r}} \frac{\partial}{\partial \mathrm{r}}(\mathrm{r} \rho \mathrm{v} \varepsilon)=\frac{\partial}{\partial \mathrm{x}}\left[\left(\mu+\frac{\mu_{t}}{\sigma_{\varepsilon}}\right) \frac{\partial \varepsilon}{\partial \mathrm{x}}\right]+\frac{1}{r} \frac{\partial}{\partial \mathrm{r}}\left[r\left(\mu+\frac{\mu_{t}}{\sigma_{\varepsilon}}\right) \frac{\partial \varepsilon}{\partial \mathrm{r}}\right]+\rho C_{1} S \varepsilon-\rho C_{2} \frac{\varepsilon^{2}}{k+\sqrt{v \varepsilon}}$

$+C_{1 \varepsilon} \frac{\varepsilon}{k} C_{3 \varepsilon} G_{b}+S_{\varepsilon}$

In these equations, $G_{k}$ represents the generation of turbulent kinetic energy due to the mean velocity gradients and $\mathrm{G}_{\mathrm{b}}$ is the generation of turbulence kinetic energy due to buoyancy. The contribution of the fluctuating dilatation in compressible turbulence to the overall dissipation rate has been neglected. $S_{k}$ and $S_{\varepsilon}$ are user-defined source terms. In the above equations,

$C_{1}=\max \left[0.43, \frac{\eta}{\eta+5}\right], \eta=S \frac{\varepsilon}{k}, S=\sqrt{2 S_{i j} S_{i j}}$

In turbulence modeling, $\mu_{\mathrm{t}}=\rho \mathrm{C}_{\mu} \frac{\mathrm{k}^{2}}{\varepsilon}, \mu_{\mathrm{eff}}=\mu+\mu_{\mathrm{t}}$ 
As discussed earlier, the special feature of realizable $\mathrm{k}-\varepsilon$ model is that $\mathrm{C}_{\mu}$ is not a constant, and it is calculated as,

$C_{\mu}=\frac{1}{A_{0}+A_{s} \frac{k U^{*}}{\varepsilon}}, U^{*}=\sqrt{S_{i j} S_{i j}+\widehat{\Omega}_{i j} \widehat{\Omega}_{i j}}, \widehat{\Omega}_{i j}=\Omega_{i j}-2 \varepsilon_{i j k} \omega_{k}, \Omega_{i j}=\bar{\Omega}_{i j}-\varepsilon_{i j k} \omega_{k}$

Here, $\bar{\Omega}_{\mathrm{ij}}$ is the mean rate of rotation tensor, viewed in a moving frame with angular velocity $\omega_{\mathrm{k}}$ and $\mathrm{A}_{0}=4.04, \mathrm{~A}_{\mathrm{s}}=\sqrt{6} \cos \varphi, \quad \varphi=\frac{1}{3} \cos ^{-1}(\sqrt{6} \mathrm{~W}), \quad \mathrm{W}=\frac{\mathrm{S}_{\mathrm{ij}} \mathrm{S}_{\mathrm{jk}} \mathrm{S}_{\mathrm{ki}}}{\tilde{\mathrm{S}}^{3}}, \quad \tilde{\mathrm{S}}=\sqrt{\mathrm{S}_{\mathrm{ij}} \mathrm{S}_{\mathrm{ij}}}, \mathrm{S}_{\mathrm{ij}}=$ $\frac{1}{2}\left(\frac{\partial U_{i}}{\partial x_{j}}+\frac{\partial U_{j}}{\partial x_{i}}\right)$

The model constants are $\mathrm{C}_{1 \varepsilon}=1.44, \mathrm{C}_{2}=1.9, \sigma_{\mathrm{k}}=1.0$, and $\sigma_{\varepsilon}=1.2$.

\section{Solution Procedure}

The finite volume solver, FLUENT 6.3 [11], is used to obtain the numerical solution of the two-dimensional axisymmetric compressible Reynolds averaged Navier-Stokes (RANS) equations in connection with the realizable $\mathrm{k}-\varepsilon$ model for closure of the RANS equations.

The considered steam ejector used in the present study is constructed of the primary nozzle and the ejector. The primary flow is strongly accelerated in the nozzle and hence the secondary flow is induced through the ejector. The main geometrical parts are the secondary inflow, mixing chamber, throat and diffuser as shown in Figure 1.

The discretized equations along with the initial condition and boundary conditions are solved using the segregated solution method for the segregated solver. The conservation of mass and momentum are solved sequentially and a pressure correction equation is used to ensure the conservation of momentum and the conservation of mass (continuity equation). The generated computational mesh for the considered steam ejector simulation corresponds to the measurements of $[4,10]$. The effect of grid refinement on the quality of results is tested in the present study of steam ejector, in which 6200 nodes for the first nozzle part and 16950 nodes for the second mixture part which makes a grid total number of 23150 nodes. For ideal steam flow, the saturation properties (temperature and pressure), are considered at the flow inlet. The outlet pressure boundary condition is identified at the exit. Since the flow is axisymmetric about the ejector center line, only the upper half is considered for the CFD computations.

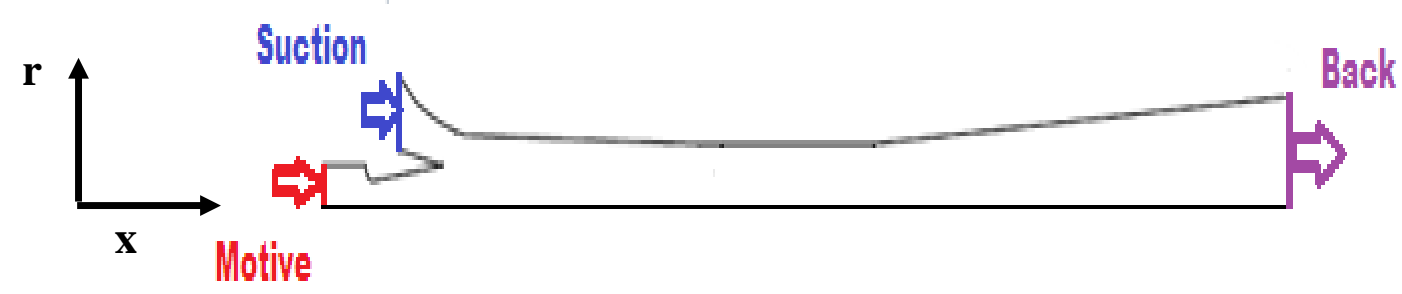

Fig. (1) Diagram of computational domain of ejector steam flow [4,10] 


\section{Results and Discussion}

The ejector performance is mainly characterized by mass ratio and the ejector efficiency.A well designed steam ejector is that can deliver the maximum attainable mass ratio with higher efficiency.The operating conditions and design geometry of the considered ejector can be found in Ref. [4,10].Figure 2 presents the code validation based on the experimental data provided by Sriveerakul[4,10]. Fig. 2 shows clearly that the presented code is able to predict the ejector performance. Also, it shows that the mass ratio is constant with back pressure increment until a certain value; in this case it is 38.5 millibars. This value is called break down point. By increasing the back pressure higher than the breakdown point a reversed flow region dominated at the ejector exit. That results in delivering the steam flow back to the suction inlet and the ejector finally malfunctions.Figures 3 and 4 represent the effect of increasing the suction pressure on the mass ratio and ejector efficiency, respectively. Raising the suction pressure results in magnifying the difference between the pressure at the nozzle exit and suction pressure, which leads to performance enhancement. Moreover, lowering the suction pressure decreases the mass ratio until reaching a zero mass ratio when the pressure at the nozzle exit is almost equal to 0.012 bar. The mass ratio is almost constant with the back pressure increment until it reaches the break down point where it decreases due to reverse flow at the ejector exit as shown in Fig. 3. The ejector efficiency is enhanced significantly with increasing the back pressure to thebreakdown point. The operation lines in Figs. 3 and 4 can be used to take the operational conditions and boundaries for the steam ejector usage.By inspectingthe back pressure for breakdown and maximum efficiency points in Figs. 3 and 4, it can be figured out that the maximum efficiency point on the operation line is likely to occur just prior to the breakdown point. That is because the back pressure increment increases the ejector efficiency more significant over its mass ratio as provided by Eqn. (5). The effect of back and motive pressures on the ejector mass ratio and efficiency at suction pressure of 0.06 bar are shown in Figs.5 and 6. It is found that by increasing the motive pressure, the back pressure range for the ejector is enlarged, but its mass ratio diminishes. Moreover, ejector efficiency gets better with increasing the motive and back pressure unit the reverse flow occurrence. Figure 7 represents the velocity vector at $\mathrm{pm}=2.7$ bar and $\mathrm{ps}=0.125$ bar. It is also clear from Fig.7 that severe turbulence is formed due to entrainment at the nozzle outlet.

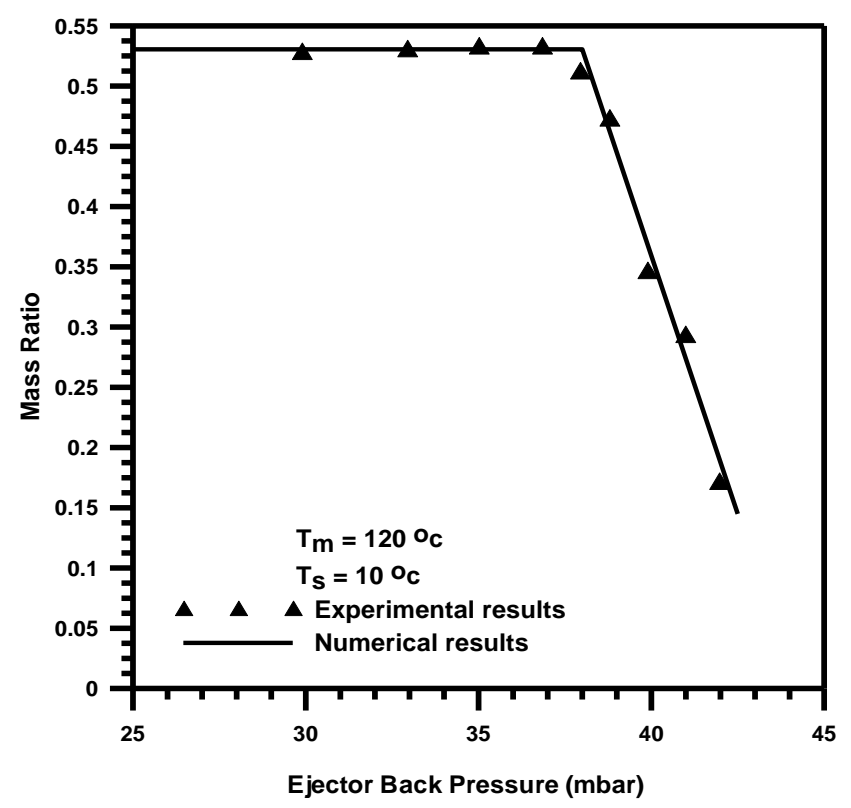

Fig. 2. Effect of back pressures on performance of a steam ejector based on experimental data provided by Sriveerakul et al. $[4,10]$. 


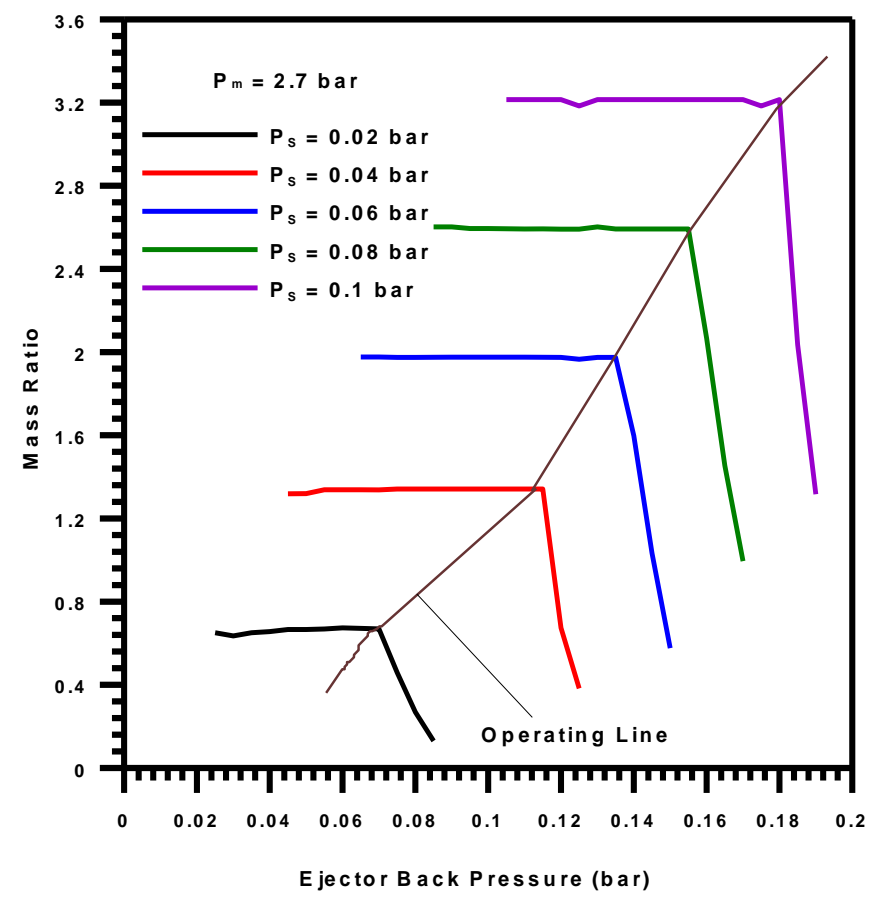

Fig. 3. Effect of suction pressure on the mass ratio at $\mathrm{p}_{\mathrm{m}}=2.7$ bar



Ejector B ack Pressure (bar)

Fig. 4. Effect of suction pressure on the ejector efficiency at $\mathrm{p}_{\mathrm{m}}=2.7 \mathrm{bar}$ 


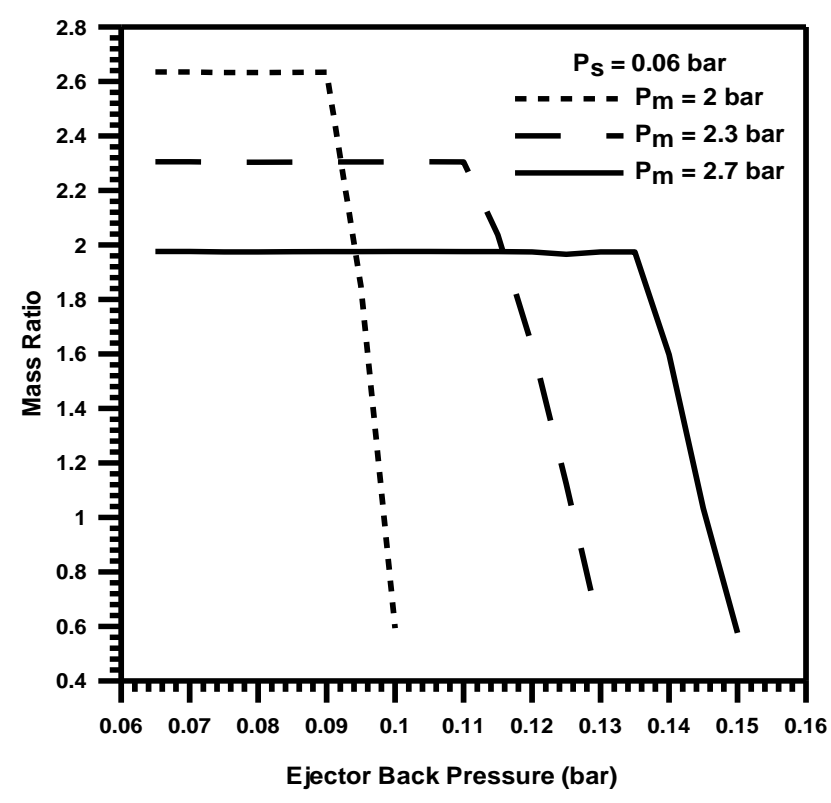

Fig. 5. Effect of motive pressure on the mass ratio at $\mathrm{ps}=0.06 \mathrm{bar}$

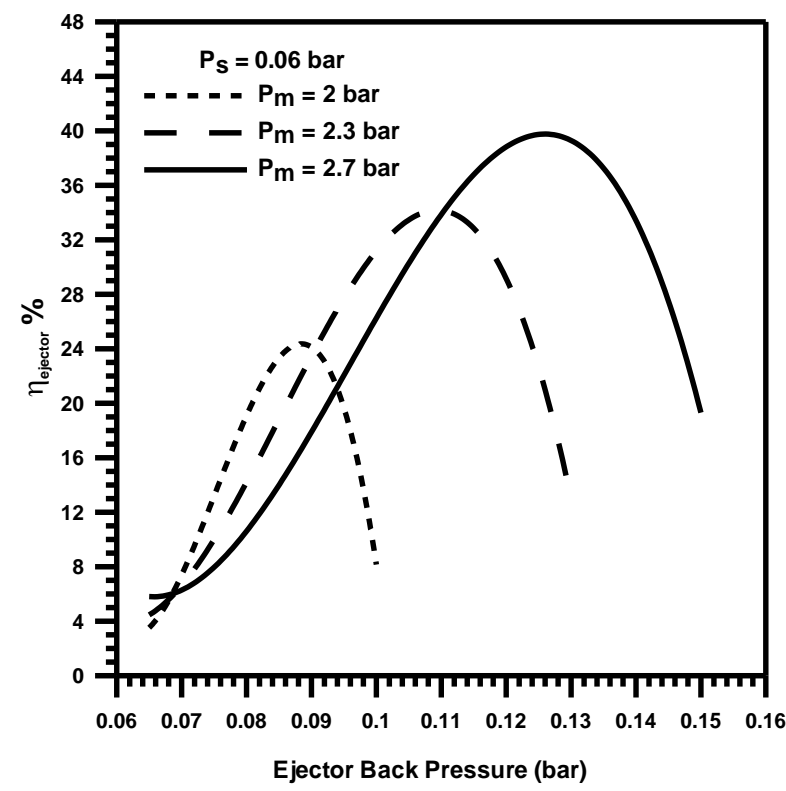

Fig. 6. Effect of motive pressure on the ejector efficiency at $\mathrm{ps}=0.06$ bar 


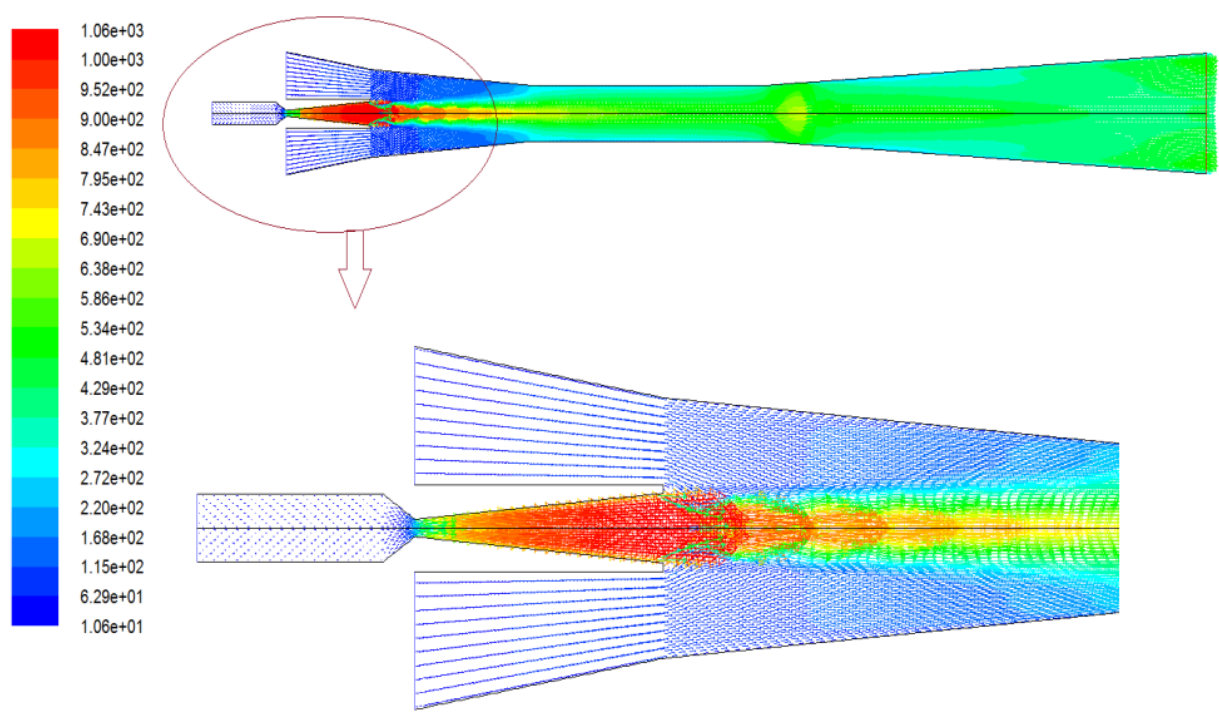

Fig. 7 Velocity vector contours by velocity magnitude $(\mathrm{m} / \mathrm{s})$ at $\mathrm{pm}=2.7$ bar and $\mathrm{ps}=0.125 \mathrm{bar}$

\section{Conclusions:}

This paper presents a comparison study for testing the steam ejector working in different operating conditions. The CFD code provides a good agreement with the available experiments. The results leads to concluding that, there are operational and geometrical constraints for using the steam ejector.

\section{References}

[1] K. Pianthong, W. Sheehanam, M. Behnia, T. Sriveerakul, S. Aphornratana, Investigation and improvement of ejector refrigeration system using computational fluid dynamics technique, Energ. Convers. Manage. 48 (9) (2007), pp. 2556-2564.

[2] E. Rusly, L. Aye, W.W.S. Charters, A. Ooi, CFD analysis of ejector in a combined ejector cooling system, Int. J. Refrig. 28 (7) (2005), pp. 1092-1101.

[3] S. Varga, A.C. Oliveira, B. Diaconu, Influence of geometrical factors on steam ejector performance-A numerical assessment, Int. J. Refrig. 32 (7) (2009), pp. 1694-1701.

[4] T. Sriveerakul, S. Aphornratana, K. Chunnanond, Performance prediction of steam ejector using computational fluid dynamics: part 2. Flow structure of a steam ejector influenced by operating pressures and geometries, Int. J. Therm. Sci. 46 (8) (2007), pp. 823-833.

[5] S. Varga, A.C. Oliveira, B. Diaconu, Numerical assessment of steam ejector efficiencies using CFD, Int. J. Refrig. 32 (6) (2009), pp. 1203-1211.

[6] "Numerical simulation and performance of steam ejector using CFD", American sceintifc publishing.

[7] S.B. Riffat, S.A. Omer, CFD modeling and experimental investigation of an ejector refrigeration system using methanol as the working fluid, International Journal of Energy Reservation 25 (2001) 115-128.

[8] E. Rusly, A. Lu, W.W.S. Charters, A. Ooi, K. Pianthong, Ejector CFD modeling with real gas model, in: Mechanical Engineering Network of Thailand the 16th Conference, 2002, pp. 150-155.

[9] X. Yang, X. Long*, X. Yao, "Numerical investigation on the mixing process in a steam ejector with different nozzle structures", International Journal of Thermal Sciences 56 (2012), pp. 95-106. 
[10] T. Sriveerakul, S. Aphornratana, K. Chunnanond, "Performance prediction of steam ejector using computational fluid dynamics: Part 1. Validation of the CFD results", International Journal of Thermal Sciences 46 (2007), pp.812-822.

[11] S. Aphornratana, I.W. Eames, A small capacity steam-ejector refrigerator: experimental investigation of a system using ejector with movable primary nozzle, International Journal of Refrigeration 20 (5) (1997) 352-358.

[12] K. Chunnanond, S. Aphornratana, An Experimental investigation of a steam ejector refrigerator: the analysis of the pressure profile along the ejector, Applied Thermal Engineering 27 (2004) 311-322.

[13] Jun-De Li, "CFD simulation of water vapour condensation in the presence of noncondensable gas in vertical cylindrical condensers", International Journal of Heat and Mass Transfer 57 (2013), pp. 708-721.

[14] Ansys Fluent 16 theory's guide, 2014.

[15] F. Liu, "Review on Ejector Efficiencies in Various EjectorSystems", International Refrigeration and Air ConditioningConference, Paper 1533 (2014).

[16] M. S. Farag "Use of Ejecting Refrigeration for Cooling Steam Plant Condenser" A Ph.D thesis in MPED, Menoufia University, 2016.

[17] T.H. Shih, W.W. Lou, A. Shabbir, Z. Yang, J. Zhou, A new k-e eddy viscosity model for high Reynolds number turbulent flow-model development and validation, Comput. Fluids 24 (3) (1995) 227-238. 